\title{
RT-PCR from Archival Single Cells Is a Suitable Method to Analyze Specific Gene Expression
}

\author{
Georgia Lahr
}

\author{
Laser Laboratory and Molecular Biology, First Medical Department, Academic Hospital München-Harlaching, \\ Munich, Germany (Lab Invest 2000, 80:1477-1479).
}

$T$ he ability to study preserved tissues at the molecular level makes possible retrospective studies on large numbers of patients and may permit tracking, over long periods of time, of genetic changes or infectious agents that are associated with diseases. The most common method for preserving human and animal tissue is fixation in formalin followed by paraffin embedding. Many different methods for RNA isolation and reverse transcriptase-polymerase chain reaction (RT-PCR) analysis from cryopreserved and archival tissue were published over the past 15 years (Bernsen et al, 1998; Jin et al, 1999). In this report it is shown that total RNA sufficient as a template for RT-PCR can be isolated in less than 30 minutes, even from single laser-microdissected cells derived from $5-\mu \mathrm{m}$-thick sections of tissue prepared for routine histopathological examination. Furthermore, cytocentrifuged and immunocytochemically stained cells of the SW480 tumor cell line were isolated by laser microdissection. Although the extracted RNA is not intact because of strand breaks, it is suitable for RT followed by nested PCR amplification. In addition, point mutations at codon 12 of the Ki-ras2 transcript, but not at codon 13, were detected as shown, for example, in seven pooled single microdissected archival colon adenocarcinoma cells and in the SW480 tumor cell line.

One of the key end points for understanding the molecular basis of carcinogenesis is the analysis of gene expression in specific cell populations. Microdissection techniques allow extraction of morphologically distinct cells for molecular analysis (Emmert-Buck et al, 1996). In the present study, a recent advance in microdissection was used, which allows precise removal of pure cell populations from morphologically preserved cells and tissue sections (Schütze and Lahr, 1998). A differentiated colon adenocarcinoma was removed immediately after colectomy, formalin-fixed, and then paraffin embedded. Serial sections (5 $\mu \mathrm{m}$ thick) were mounted onto a $0.1 \%$ Poly-L-lysinecoated (Sigma, Deisenhofen, Germany) 1.35- $\mu \mathrm{m}$-thin

Received June 21, 2000.

Address reprint requests to: G. Lahr, Laserlabor und Molekularbiologie, Städt Krankenhaus München-Harlaching, I. Med. Abteilung, Sanatoriumsplatz 2, D-81545 München, Germany. Fax: 49896427 2805; E-mail: G.Lahr@extern.lrz-muenchen.de polyethylene foil (P.A.L.M. GmbH, Bernried, Germany), which was attached to a supporting slide. The sections were deparaffinized and stained with hematoxylin-eosin as usual for microscopic examination (Fig. 1A). As a control, the permanent growing colon carcinoma tumor cell line SW480 was used (Schütze and Lahr, 1998). After cytocentrifugation on conventional glass slides, the SW480 cells were fixed and stained with the EPIMET Epithelial Cell Detection Kit (Baxter, Heidelberg, Germany). The kit is based on the reactivity of the murine monoclonal antibody A45B/B3 with the epithelial cell's cytoskeleton (Pantel et al, 1994). The laser microbeam of the RobotMicroBeam system (P.A.L.M. $\mathrm{GmbH}$ ) was focused through a $40 \times$ dry long-distance objective lens of an inverted microscope (Axiovert 135; Carl Zeiss, Göttingen, Germany). Using laser microbeam microdissection (LMM), the distinct tumor cells were separated from the adjacent tissue yielding a $1 \mu \mathrm{m}$-sized, material-free gap between the selected and nonse-
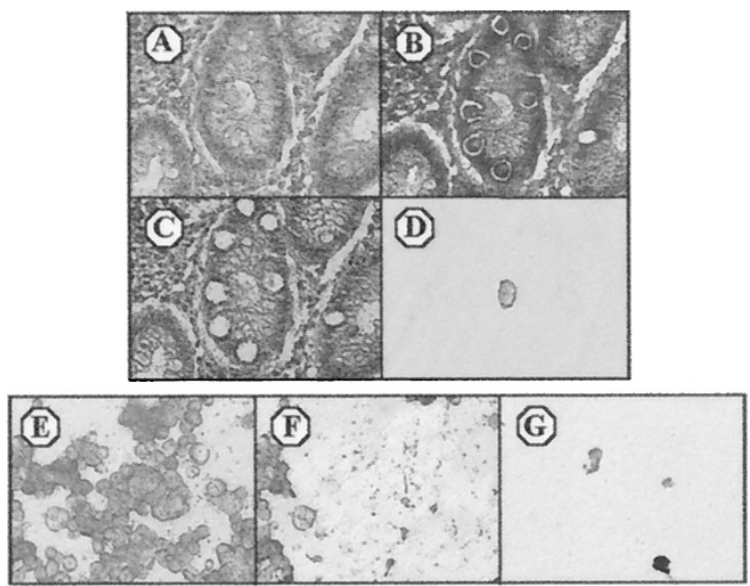

Figure 1.

Microscopic illustration of one specific experiment using laser microbeam microdissection (LMM) and laser pressure catapulting (LPC) to capture pooled single cells from membrane-mounted archival hematoxylin-eosin-stained tissue slices of a differentiated colon adenocarcinoma $(A$ to $D)$ and cytocentrifuged immunocytochemically stained SW480 cells from conventional glass slides $(E$ to $G)$. The view shows a specimen before LMM ( $A$ and $E$ ), the remaining tissue after LMM $(B)$, the remaining tissue or cells after LPC $(C$ and $F$ ), and the catapulted and captured cells in the cap of a conventional microfuge tube $(D$ and $G)$. $(\times 40$ objective $)$ 


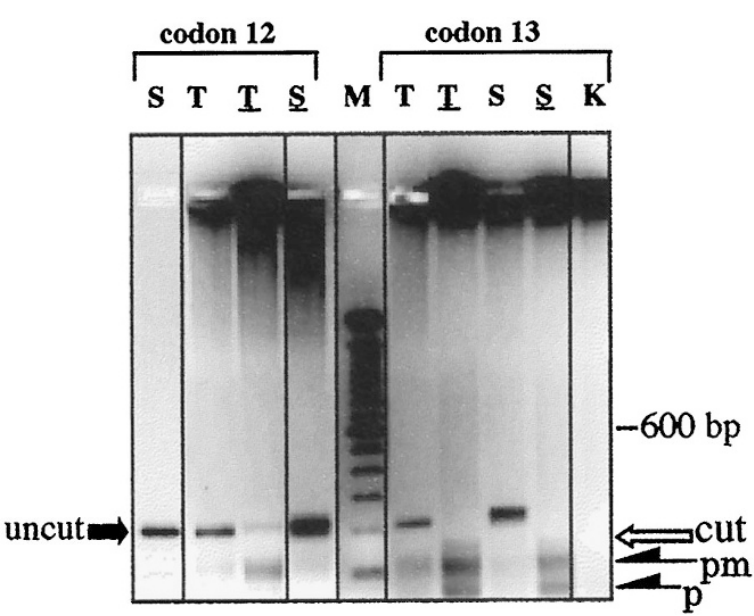

Figure 2.

Mspl-digest of Ki-ras2 reverse transcriptase-polymerase chain reaction (RTPCR)-amplified products loaded on a 1.5\% ethidiumbromide-stained agarose gel after laser microdissection of 7 pooled tumor cells and about 100 SW480 cells (Fig. 1). Left side, Codon 12 analysis (217 bp RT-PCR fragments); right side, codon 13 analysis (214 bp). The uncut and cut RT-PCR fragments, as well as the bands corresponding to primer multimers (pm) and to primers (p), are indicated. T, RT-PCR sample of 7 pooled tumor cells; $\underline{T}$, Mspl-digest of (T); S, RT-PCR sample of about 100 isolated SW480 cells; $\underline{\mathrm{S}}$, (S) digested with Mspl; $M, 100$ bp ladder size marker; $K$, control containing $\mathrm{H}_{2} \mathrm{O}$ instead of DNA.

lected area (Fig. 1B). The laser energy was set to cut both the tissue and the supporting membrane. Laser pressure catapulting (LPC) was performed with a single shot to catapult the cells in a contact-free manner into a common microfuge cap moistened with a $2 \mu \mathrm{l}$ droplet of mineral oil (Fig. 1D), which was held and centered above the line of laser fire by a special collector device. As a control, approximately 100 SW480 cells (Fig. 1E) were catapulted directly from the glass slide (Fig. 1F). Because of the red staining, these cells and the fragments thereof were easy to detect in the collecting cap (Fig. 1G).

To test the reproducibility of the method, a duplicate series of microdissected tumor cells (1-30 cells), as well as different numbers of SW480 cells (1-7 cells), were analyzed by RT-PCR analysis. Colon adenocar- cinoma cells and SW480 cells (including the cells shown in Fig. 1, D and G) were simply covered with a $30 \mu$ lysis buffer included in the PUREscript RNAisolation Kit (BIOzym Diagnostik, Hessisch Oldendorf, Germany). Instead of laser microdissection, manually dissected cell preparations can also be used for further analysis (Lahr et al, 1999). The microdissected cells were lysed by repeated pipetting steps. Then the caps were topped with the remaining tube, and total RNA from laser-microdissected cells was isolated according to the manufacturer's protocol in less than 30 minutes. The extracted RNA was either dissolved in $50 \mu \mathrm{l}$ (50-100 SW480 cells) or in $5 \mu \mathrm{l}$ (smaller number of SW480 and tumor cells) RNA hydration solution supplied by the manufacturer. cDNA synthesis from the RNA was performed with the ExpeRT-PCR Kit (Hybaid-AGS, Heidelberg, Germany), with the two step protocol in a $25 \mu$ l reaction volume using $5 \mu \mathrm{l}$ (tumor cells) or $10 \mu \mathrm{l}$ (SW480) total RNA and $2 \mu \mathrm{l} 10 \times$ random hexamers (Roche Diagnostics $\mathrm{GmbH}$, Mannheim, Germany). The reaction was incubated for 60 minutes at $42^{\circ} \mathrm{C}$.

In comparison with our previously published work using the Titan Kit (Roche Molecular Biochemicals, Mannheim, Germany) and gene-specific oligonucleotides, RT now can be primed "nonspecifically" with universal primers such as random hexamers or oligo dT (Schütze and Lahr, 1998). This method allows the analysis of multiple expressed genes from one cell preparation. PCR amplification was performed with the ExpeRT-PCR system with 20 pmol each of the "outer" primer set 13s/12a (Schütze and Lahr, 1998). The samples were subjected to 40 cycles of $93^{\circ} \mathrm{C}$ for 1 minute, of $63^{\circ} \mathrm{C}, 62^{\circ} \mathrm{C}$, and $61^{\circ} \mathrm{C}$ for 1 minute each, of $72^{\circ} \mathrm{C}$ for 2 minutes, and of $72^{\circ} \mathrm{C}$ for 15 minutes, with storage at $4^{\circ} \mathrm{C}$. The nested PCR amplifications were performed in a $50 \mu \mathrm{l}$ volume with a $10 \mu \mathrm{l}$ aliquot of the 1st PCR product containing 20 pmoles of "inner" primer sets 12s/13a (codon 12) and 13Cs/13a (codon 13) (Schütze and Lahr, 1998) using the conditions mentioned above. One aliquot of the 2nd Ki-ras2 PCR reaction, as shown for the 7 pooled tumor cells

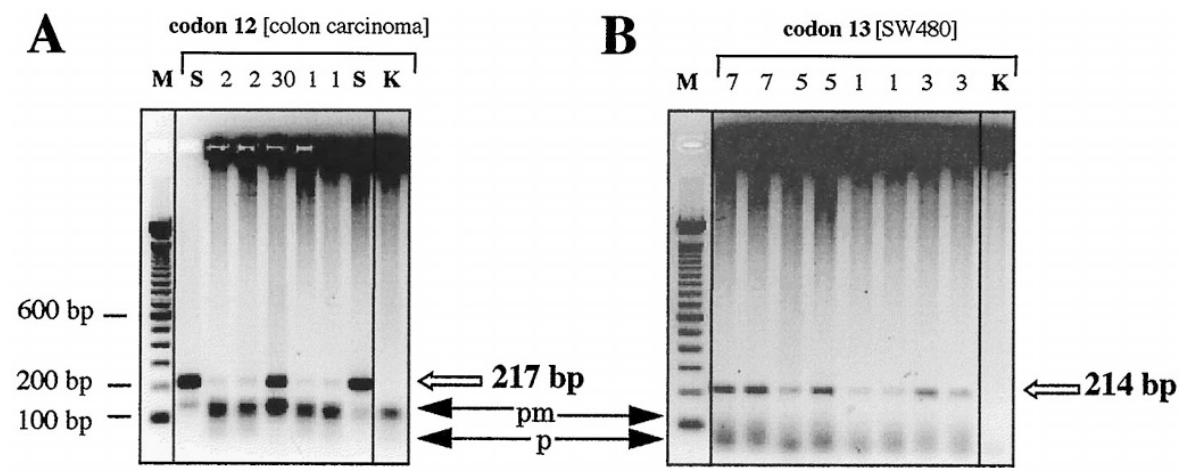

\section{Figure 3.}

Ki-ras2 RT-PCR-amplified products of "duplicate" samples of microdissected cells loaded on a $1.5 \%$ ethidiumbromide-stained agarose gel. The specific number of single or pooled tumor cells is indicated above the figure. A, Codon 12-specific RT-PCR fragments of colon carcinoma tumor cells. $B$, Codon 13-specific RT-PCR fragments of SW480 tumor cells. The size of the RT-PCR fragments, as well as the bands corresponding to primer multimers (pm) and to primers ( $p$ ), are indicated $S$, RT-PCR sample of about 50 microdissected SW480 cells; $M, 100$ bp ladder size marker; $K$, control containing $\mathrm{H}_{2} \mathrm{O}$ instead of DNA. 
(Fig. 1D) and the 100 pooled and immunostained SW480 cells (Fig. 1G), was digested with the restriction enzyme Mspl (New England Biolabs, Schwalbach/ Taunus, Germany). Also single-cell restriction analysis can be performed (Schütze and Lahr, 1998). Mspl cuts within the 217 (codon 12) or 214 bp (codon 13) PCR fragment, only if codon 12 or 13 is wild type (Haliassos et al, 1989). Controls containing $\mathrm{H}_{2} \mathrm{O}$ instead of RNA/ DNA were always run in parallel. The products of the nested PCR and the Mspl digests were fractionated on $1.5 \%$ agarose gels containing $0.25 \mu \mathrm{g} / \mathrm{ml}$ ethidiumbromide to yield DNA fragments of the appropriate length (Figs. 2 and 3). The validity of our modified Ki-ras2 primer method was demonstrated with the SW480 tumor cell line that differs from the wild-type Ki-ras2 at codon 12, but not at codon 13 (Jiang et al, 1989; Verlaan-de Vries et al, 1986). Therefore, the SW480 cell line can be used as a positive control for mutation analysis of Ki-ras2 codon 12 as is indicated in the data sheet for this cell line (ATCC, 2000). Because mutant Ki-ras2 is not found in nonmalignant disease, detection here of mutant Ki-ras2 in colon disease provides an additional diagnostic tool for colon adenocarcinomas.

In conclusion, the use of archival, formalin-fixed, paraffin-embedded tissue is an invaluable resource for molecular genetic studies. It is shown that neither histological tissue preparation method, ie, neither fixation nor staining (including immunostaining), negatively impacts RNA recovery, which is in agreement with the study of Mies (Mies, 1994). Included chemicals that might inhibit RT are overcome by purification of the "cell extracts" by RNA isolation. This rapid laser-based microdissection technique, in combination with the above described "oligo- or single-cell" RNA isolation and RT-PCR protocol, allows the convenient analysis of archival as well as native samples from patients. This is an important step forward in the acquisition of knowledge about the molecular defects that are responsible for acquired or inherited diseases.

\section{References}

ATCC (American Type Culture Collection) data sheet of the SW480 cell line. http://phage.atcc.org/cgi-bin/searchengine/ longview.cgi? view $=$ ce,346510\&text $=$ SW480. Accessed July 21, 2000.
Bernsen MR, Dijkman HBPM, de Vries E, Vigdor CG, Ruiter DJ, Adema GJ, and Muijen GN (1998). Identification of multiple mRNA and DNA sequences from small tissue samples isolated by laser-assisted microdissection. Lab Invest 78:1267-1273.

Emmert-Buck MR, Bonner RF, Smith PD, Chuaqui RF, Zhuang Z, Goldstein SR, Weiss RA, and Liotta LA (1996). Laser capture microdissection. Science 274:998-1001.

Haliassos A, Chomel JC, Grandjouan S, Kruh J, Kaplan JC, and Kitzis A (1989). Detection of minority point mutations by modified PCR technique: A new approach for a sensitive diagnosis of tumor-progression markers. Nucleic Acids Res 17:8093-8099.

Jiang W, Kahn SM, Guillen JG, Lu S-H, and Weinstein B (1989). Rapid detection of ras oncogenes in human tumors: Applications to colon, esophageal, and gastric cancer. Oncogene 4:923-928.

Jin L, Thompson CA, Qian X, Kuecker SJ, Kulig E, and Lloyd RV (1999). Analysis of anterior pituitary hormone mRNA expression in immunophenotypically characterized single cells after laser capture microdissection. Lab Invest 79:511512.

Lahr G, Stich M, Schütze K, Blümel P, Zwicknagl M, Spelsberg F, Pösl H, and Nathrath WBJ (1999). Diagnosis of papillary thyroid carcinoma is facilitated by using a RT-PCR approach on laser-microdissected archival material to detect RET oncogene activation. Virchows Arch 435:293.

Mies C (1994). A simple, rapid method for isolating RNA from paraffin-embedded tissues for reverse transcriptionpolymerase chain reaction (RT-PCR). J Histochem Cytochem 42:811-813.

Pantel K, Schlimok G, Angstwurm M, Weckermann D, Schmaus W, Gath H, Passlink B, Izbicki JR, and Riethmüller G (1994). Methodological analysis of immunocytochemical screening for disseminated epithelial tumor cells in bone marrow. J Hematother 3:165-173.

Schütze K and Lahr G (1998). Identification of expressed genes by laser-mediated manipulation of single cells. Nat Biotechnol 16:737-742.

Verlaan-de Vries $M$, Bogaard ME, van den Elst $\mathrm{H}$, van Boom $\mathrm{JH}$, van der Eb AJ, and Bos $\mathrm{JL}$ (1986). A dot-blot screening procedure for mutated ras oncogenes using synthetic oligodeoxynucleotides. Gene 50:313-320. 